\title{
STABLE CARBON AND OXYGEN ISOTOPIC COMPOSITION OF MIO- PLIOCENE BIVALVE SHELLS AND CALCAREOUS SEDIMENTS IN NHILA ANTICLINE, SOUTHEAST BENGAL BASIN, BANGLADESH
}

\author{
H. M. Zakir Hossain ${ }^{1}$, Md. Sultan-Ul-Islam ${ }^{2}$, John S. Armstrong-Altrin ${ }^{3}$, Alcides N. Sial ${ }^{4}$, Sabbir \\ Ahamed $^{1}$, Md. Nahid Nowsher ${ }^{1}$, Md. Abdullah-Al-Kawsar ${ }^{2}$ \\ ${ }^{1}$ Department of Petroleum and Mining Engineering, Jessore University of Science and Technology, Jessore-7408, \\ Bangladesh \\ ${ }^{2}$ Department of Geology and Mining, University of Rajshahi, Rajshahi-6205, Bangladesh \\ ${ }^{3}$ Instituto de Ciencias del Mar y Limnología, Unidad de Geología Marina y Ambiental, Universidad Nacional \\ Autónoma de México, Circuito Exterior s/n, 04510, Mexico DF, Mexico \\ ${ }^{4}$ Nucleo de Estudos Geoquímicos e Laboratório de Isótopos Estáveis (NEG-LABISE), Departmento de Geologia, \\ Universidade Federal de Pernambuco, Caixa Posta 7852, 50670-000 Recife, PE, Brazil \\ *Corresponding author; e-mail: zakirgsd@yahoo.com (H.M.Z. Hossain)
}

\begin{abstract}
Stable carbon $\left(\delta^{13} \mathrm{C}\right)$ and oxygen $\left(\delta^{18} \mathrm{O}\right)$ isotopes of bivalve shells and calcareous sediments of the Mio-Pliocene Nhila Anticline, southeast Bengal Basin, Bangladesh have been investigated to obtain information on paleoclimate and paleoenvironment conditions during

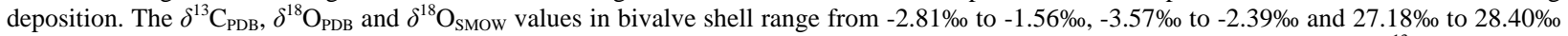
in bivalve shells and $-13.90 \%$ to $-1.75 \%$ o, $-4.71 \%$ o to $-2.13 \%$ and $26.01 \%$ o to $28.66 \%$ in calcareous sediments, respectively. The $\delta^{13} C_{\text {PDB }}$ values in bivalve shells are comparable to that of calcareous sediments ( -1.75\%o) in the upper section, but $\delta^{13} \mathrm{C}_{\mathrm{PDB}}$ values in calcareous sediments are more negative excursion towards lower section (up to $-13.90 \%$ ). These results signify that salinity gradients could modified the isotope values and/or strong influence of freshwater conditions. The variable $\delta^{18} \mathrm{O}_{\mathrm{PDB}}$ values in both bivalve shell and calcareous sediment suggesting diagenetic alteration of carbonates and water temperature effects. The more negative $\delta^{18} \mathrm{O}_{\mathrm{PDB}}$ values imply humid paleoclimatic conditions during the MioPliocene sedimentation. Therefore, the $\delta^{18} \mathrm{O}_{\mathrm{PDB}}$ values of the Mio-Pliocene sediments of Nhila Anticline are probably controlled by paleotemperature leading to intensification of high rainfall.
\end{abstract}

Key words: Stable isotopes, bivalve shells, calcareous sediments, Bengal Basin, Bangladesh

সারাংশ: পললায়নকালে প্রাচীন পরিবেশের ও আবহাওয়া বৈশিষ্ট্য জানার জন্য দক্ষিণপূর্ব বঙ্গ বেসিনের হ্নীলা ভূ-উর্ধভাঁজে মায়ো-প্লায়োসিন কালের ঝিনুক জাতীয় প্রাণীর খোলস ও চুনময় পললের স্থায়ী কার্বন ও অক্সিজেন আইসোটপের সংযুতি নির্ণয় করা হয়। ঝিনুক জাতীয় প্রাণীর খোলসের $\delta^{13} \mathrm{C}_{\mathrm{PDB}}, \delta^{18} \mathrm{O}_{\mathrm{PDB}}$ এবং $\delta^{18} \mathrm{O}_{\mathrm{SMOW}}$ মান যথাক্রনে -২.৮-১\% হতে -১.৫৬\%, -৩.৫৭\% হতে -২.৩৯\% এবং ২৭.১৮\% হতে ২৮.৪০\%। কিন্তু চুনময় পলনে সে মানগুলি -১৩.৯০\% হতে -১.৭৫\%; -৪.৭১\% হতে -২.১৩\% এবং ২৬.০১\% হতে ২৮.৬৬\%। এসব আইসোটপের মান পললায়ন বেসিনে লবণাক্ততার মান অত্যন্ত উল্লেখযোগ্যভাবে বিক্্দ্ধ অলবণাক্ত পানির দ্বারা পরিবর্তিত হবার ইংগিত প্রদান করে। এছাড়াও সে সময়ে আর্দ্র আবহাওয়া ও প্রচুর বৃষ্টিপাতের ইংগিতও পাওয়া যায়।

\section{Introduction}

The Bengal Basin is located in the northeastern most part of the Indian subcontinent, occupying whole Bangladesh, west Bengal, Assam, Tripura and part of Myanmar. It has been originated between the collision of Indian, Eurasian and Burmese plates building the extensive Himalayan Mountain Belt to the north and Indo-Burma Ranges to the east (Fig. 1). This basin lies between the latitudes $20^{\circ} 34^{\prime}$ to $26^{\circ} 38^{\prime} \mathrm{N}$ and the longitudes $88^{\circ} 01^{\prime}$ to $92^{\circ} 41^{\prime}$ E. Sedimentation of the basin comprises $\sim 22 \mathrm{~km}$ thick in its central part (Alam et al., 2003; Hossain et al., 2010). The Bengal Basin has been divided into three geo-tectonic provinces such as the Stable Shelf, the Central Deep Basin and the Chittagong-Tripura folded belt (Alam et al., 2003).

Tectonically, the study area is situated in Nhila Anticline of the Chittagong-Tripura Folded Belt, southwest Bengal Basin, Bangladesh (Fig. 1). This fold belt increases eastward, subsequently merging with the
Indo-Burman Ranges (Uddin and Lundberg, 1999). The studied Nhila Anticline is $28 \mathrm{~km}$ away from the Cox's Bazar district, and is very close to the international border of Myanmar (Fig. 1). The stratigraphy of the southeast Bengal Basin of Bangladesh is shown in Table 1. The lithostratigraphic succession of the studied Nhila Anticline area is subdivided into the Bhuban, Boka Bil and Tipam Sandstone Formations in ascending order of Miocene to Pliocene in age. The Bhuban Formation consists mainly of sandstone, shale, silty shale and occasionally conglomerate subsequently deposited in deltaic environments. The thickness of the Formation is $>3000 \mathrm{~m}$ (Gani and Alam, 2003). The overlying Boka Bil Formation consists predominantly of shale, silty shale with subordinate siltstone and sandstone. Depositional environment of the formation was also deltaic. The thickness of the Boka Bil Formation is $1500 \mathrm{~m}$ (Gani and Alam, 2003). The contact between the Boka Bil Formation and overlying Tipam Sandstone Formation is errosional. 


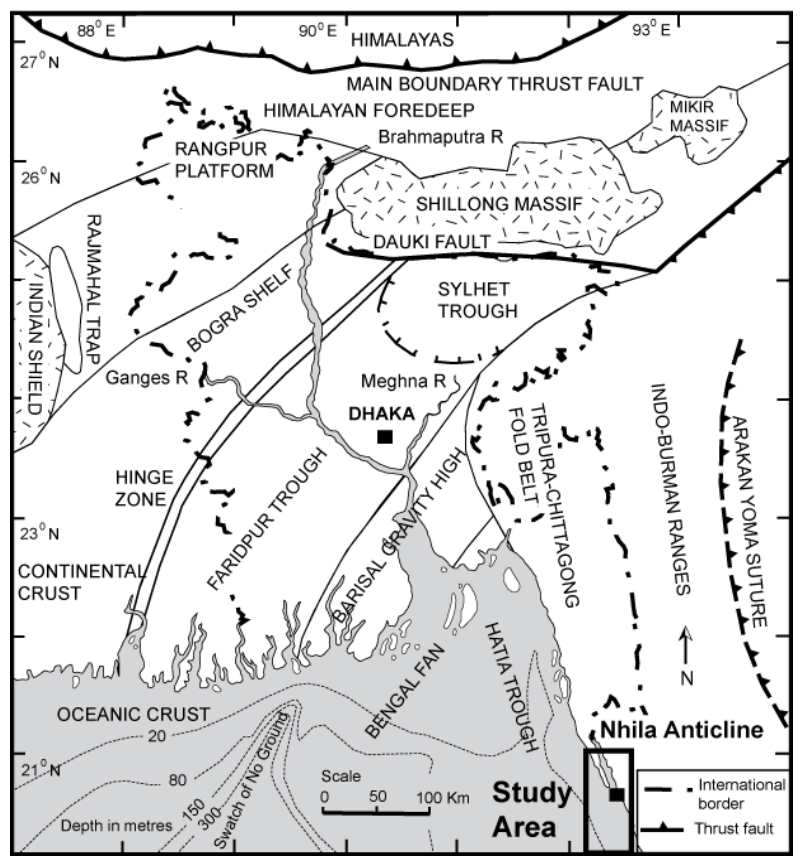

Fig. 1 Location map of the study area showing major tectonic features of Bengal Basin and adjoining areas (modified after Alam et al., 1990; Khan, 1991; Reimann, 1993).
The Tipam Sandstone Formation comprises mainly of sandstone with shale, siltstone and occasionally conglomerate subsequently deposited in braided river environment under fluvial regime (Gani and Alam, 2003; Alam et al., 2003; Roy and Roser, 2011).

Stable carbon and oxygen isotopes are widely used to evaluate the diagenetic environment and depositional processes (Armstrong-Altrin et al., 2011). Carbon isotopic compositions of pedogenic carbonates have been shown to reflect changes in atmospheric $p \mathrm{CO}_{2}$ levels over geologic timescale (Cerling, 1991; Robinson et al., 2002). Oxygen isotopic compositions of carbonates are much prone to alteration during diagenesis and/or post-depositional modifications (Hudson, 1977; Viezer, 1983). However, the isotopic composition of soil $\mathrm{CO}_{2}$ is largely controlled by the proportion of surface plant biomass using the $C_{3}$ (Calvin cycle) or $\mathrm{C}_{4}$ (Hatch-Slack) photosynthetic pathways (Cerling, 1984; Alam et al., 1997).

Stable isotope study is rare in the Bengal Basin of Bangladesh. Therefore, the objective of this study is to evaluate paleoclimate and paleoenvironment proxies using stable carbon $\left(\delta^{13} \mathrm{C}\right)$ and oxygen $\left(\delta^{18} \mathrm{O}\right)$ isotopes of bivalve shells and calcareous sediments of the Nhila Anticline, southeast Bengal Basin, Bangladesh.

Table 1 Stratigraphy of southeast Bengal Basin, Bangladesh (after Evans, 1932; Gani and Alam, 2003; Roy and Roser, 2011).

\begin{tabular}{|l|l|l|l|l|l|}
\hline Age (approx.) & Group & Formation & Lithology & $\begin{array}{l}\text { Depositional } \\
\text { environment }\end{array}$ & $\begin{array}{l}\text { Thickness } \\
\text { (approx. m) }\end{array}$ \\
\hline Recent & Alluvium & Alluvium & Sand, silt, clay & - & - \\
\hline Plio-Pleistocene & Dupi Tila & Dupi Tila & Sandstone, shale & Meandering & 500 \\
\hline \multirow{2}{*}{ Pliocene } & \multirow{2}{*}{ Tipam } & Girujan Clay & Clay, sandstone & Overbank & 200 \\
\cline { 3 - 7 } & \multirow{2}{*}{ Miocene } & Tipam Sandstone & Sandstone, shale & Braided & 900 \\
\hline & \multirow{2}{*}{ Surma } & Boka Bil & Sandstone, shale & Deltaic & 1500 \\
\cline { 3 - 7 } & & Bhuban & Sandstone, shale & Deltaic & $>3000$ \\
\hline
\end{tabular}

Based not seen

\section{Materials and Methods}

A total of 10 samples (3 bivalve shells and 7 calcareous sediments) were collected from the upper Boka Bil and Tipam Sandstone Formations in Mio-Pliocene Nhila Anticline, southeast Bengal Basin, Bangladesh.

Stable isotope analyses were performed at the Stable Isotope Laboratory (LABISE) of the Federal University of Pernambuco, Brazil. Detailed sample preparation and analytical techniques are illustrated in Armstrong-Altrin et al. (2011), but are also summarized below. $\mathrm{CO}_{2}$ was removed from powdered carbonates in a high vacuum line after reaction with $\mathrm{H}_{3} \mathrm{PO}_{4}$ at $25{ }^{\circ} \mathrm{C}$, and cryogenically cleaned based on the technique explained by Craig (1957). The SMOW (Standard Mean Ocean Water) conversion values to PDB (Peedee Belemnite) standard were carried out using the following equation $\delta^{18} \mathrm{O}_{\text {calcite }}(\mathrm{SMOW})=1.03086 \delta^{18} \mathrm{O}_{\text {calcite }}(\mathrm{PDB})+30.86$ (Friedmnan and O’ Neil, 1997).

\section{Results and Discussion}

Average stable carbon and oxygen isotope values of Mio-Pliocene bivalve shells and calcareous sediments of the Nhila Anticline are shown in Table 2. 
The $\delta^{13} \mathrm{C}_{\mathrm{PDB}}$ values for bivalve shell illustrate negative excursion, range from $-2.81 \%$ to $-1.56 \%$ o (av. -2.19\%o), while $\delta^{13} \mathrm{C}_{\mathrm{PDB}}$ values for calcareous sediments show more negative excursion, varies from $-13.90 \%$ to 1.75\%o, (av. -7.56\%) (Table 2). Armstrong-Altrin et al. (2001) reported that $\delta^{13} \mathrm{C}_{\mathrm{PDB}}$ values in the modern carbonates from the Kudankulam Formation, Tamil Nadu have positive excursion, ranging from $0 \%$ o to $4 \%$. In this study, the negative $\delta^{13} \mathrm{C}_{\mathrm{PDB}}$ values in the samples of Mio-Pliocene Nhila Anticline suggesting that the effects of pedogenic modification of carbonates (Bellanca, et al., 1995; Armstrong-Altrin et al., 2001), and also controlled by meteoric water conditions (Allan and Matthews, 1977, 1982). These wide variations of $\delta^{13} \mathrm{C}_{\mathrm{PDB}}$ values further indicate that salinity gradients can modify the isotope values or the strong influence of freshwater environmental conditions. The $\delta^{13} \mathrm{C}_{\mathrm{PDB}}$ of carbonate is always show wide range of variation that is more related to plant photosynthetic pathways (Cerling, 1984; Cerling et al., 1989; Alam et al., 1997). However, the elevated algal population and photosynthetic activity in the shallow marginal marine environment can give positive $\delta^{13} \mathrm{C}$ values (Milliman and Muller, 1977; Nelson, 1988; Armstrong-Altrin et al., 2011).
The $\delta^{18} \mathrm{O}_{\mathrm{PDB}}$ values for bivalve shells and calcareous sediments range from $-3.57 \%$ o to $-2.39 \%$ (av. $-3.08 \%$ ) and $-4.71 \%$ o to $-2.13 \%$ o (av. $-3.58 \%$ ), respectively (Table 2). Similarly, $\delta^{18} \mathrm{O}_{\text {SMOw }}$ values in both bivalve shells and calcareous sediments range from $27.18 \%$ o to $28.40 \%$ (av. 27.69\%o) and 26.01\% to 28.66\% (av. $27.17 \%$ ), respectively (Table 2). The negative $\delta^{18} \mathrm{O}_{\mathrm{PDB}}$ values in the both bivalve shells and calcareous sediments indicate post-depositional modification and/or meteoric water diagenesis (Keith and Weber, 1964; Veizer and Demovic, 1973; Nagarajan et al., 2008; Armstrong-Altrin et al., 2011; Hossain et al., 2012). Dettman et al. (2001) reported that high rainfall and wet seasonal climatic conditions are linked with the most negative $\delta^{18} \mathrm{O}_{\mathrm{PDB}}$ values. The high negative $\delta^{18} \mathrm{O}_{\mathrm{PDB}}$ values imply lower precipitation and temperature effect, whereas low negative values signify humid paleoclimatic condition. As for example, carbonate rocks of Upper Miocene Kudankulam Formation, southern India were deposited in humid paleoclimatic conditions (Armstrong-Altrin et al., 2009). However, the variable $\delta^{18} \mathrm{O}_{\mathrm{PDB}}$ values in sediments of the Nhila Anticline indicate water temperature effect, and small negative $\delta^{18} \mathrm{O}_{\mathrm{PDB}}$ values inferring humid paleoclimatic conditions during the Mio-Pliocene sedimentation in the studied area.

Table 2 Stable carbon and oxygen isotopic composition of bivalve shells and calcareous sediments of the Mio-Pliocene Nhila Anticline, southeast Bengal Basin, Bangladesh.

\begin{tabular}{llrrrrr}
\hline Sample no & Sample type & $\delta^{13} \mathrm{C}_{\text {calcite }}$ & $\delta^{18} \mathrm{O}_{\text {calcite }}$ & $\delta^{18} \mathrm{O}_{\text {calcite }}$ & $\delta^{18} \mathrm{O}_{\text {water }}(\mathrm{SMOW})^{2}$ \\
\hline GEO 1 & Calcareous sediment & -1.75 & -3.81 & 26.93 & -2.88 & -1.81 \\
GEO 2 & Calcareous sediment & -6.38 & -4.71 & 26.01 & -3.78 & -2.71 \\
GEO 4 & Bivalve shell & -1.56 & -2.39 & 28.4 & -1.46 & -0.38 \\
GEO 5 & Bivalve shell & -2.81 & -3.57 & 27.18 & -2.64 & -1.57 \\
GEO 6 & Calcareous sediment & -6.37 & -3.99 & 26.75 & -3.06 & -1.99 \\
GEO 8 & Bivalve shell & -2.19 & -3.27 & 27.49 & -2.34 & -1.26 \\
GEO 9 & Calcareous sediment & -8.81 & -2.76 & 28.02 & -1.83 & -0.75 \\
GEO 10 & Calcareous sediment & -8.9 & -4.29 & 26.44 & -3.36 & -2.29 \\
GEO 11 & Calcareous sediment & -13.9 & -2.13 & 28.66 & -1.2 & -0.12 \\
GEO 12 & Calcareous sediment & -6.78 & -3.35 & 27.41 & -2.42 & -1.34 \\
\hline
\end{tabular}

${ }^{1} \delta^{18} \mathrm{O}_{\text {calcite }}(\mathrm{SMOW})=1.03086 \delta^{18} \mathrm{O}_{\text {calcite }}(\mathrm{PDB})+30.86$ (Friedman and O’Neil, 1977).

${ }^{2}$ These values are calculated by assuming a paleotemperature of precipitation of $20{ }^{\circ} \mathrm{C}$ and $25{ }^{\circ} \mathrm{C}$ (e.g., Wright, 1987) and using the calcite paleothermometer of Friedman and O’Neil (1977).

The estimated $\delta^{18} \mathrm{O}$ values of pore waters that precipitated in the bivalve shells, ranging from $-2.64 \%$ to $-1.46 \%$ o SMOW (av. $-2.15 \%$ ) at $20{ }^{\circ} \mathrm{C}$ and $-1.57 \%$ o to -0.38\% SMOW (av. -1.07\%o) at $25{ }^{\circ} \mathrm{C}$, respectively
(Table 2). Similarly, $\delta^{18} \mathrm{O}$ values in the calcareous sediments ranging from $-3.78 \%$ to $-1.20 \%$ (av. $2.65 \%$ ) at $20{ }^{\circ} \mathrm{C}$ and $-2.71 \%$ o to $-0.12 \%$ (av. $-1.57 \%$ o) at $25{ }^{\circ} \mathrm{C}$, respectively (Table 2). Shackleton (1968) and 
Meyers and Lohmann (1985) reported that the seawater composition is inferred to have varied between $-0.5 \%$ and $+0.5 \%$ SMOW. The $\delta^{18} \mathrm{O}$ values of pore waters for the studied samples are all lower than typical seawater value, inferring the influence of meteoric water diagenesis (Armstrong-Altrin et al., 2009).

The variation diagram between $\delta^{13} \mathrm{C}_{\mathrm{PDB}}$ and $\delta^{18} \mathrm{O}_{\mathrm{PDB}}$ (Fig. 2) show poor correlation $(r=-0.20)$ with parallel or rather negative trend. Marshall (1992) and Buonocunto et al. (2002) reported that strong positive correlation between $\delta^{13} \mathrm{C}_{\mathrm{PDB}}$ and $\delta^{18} \mathrm{O}_{\mathrm{PDB}}$ imply diagenetic alteration of carbonates. The poor correlation and scatter distribution in both bivalve shells and calcareous sediments in the Nhila Anticline reflects variable degrees of burial diagenesis and/or the potential effects of meteoric waters (Quade et al., 2007).

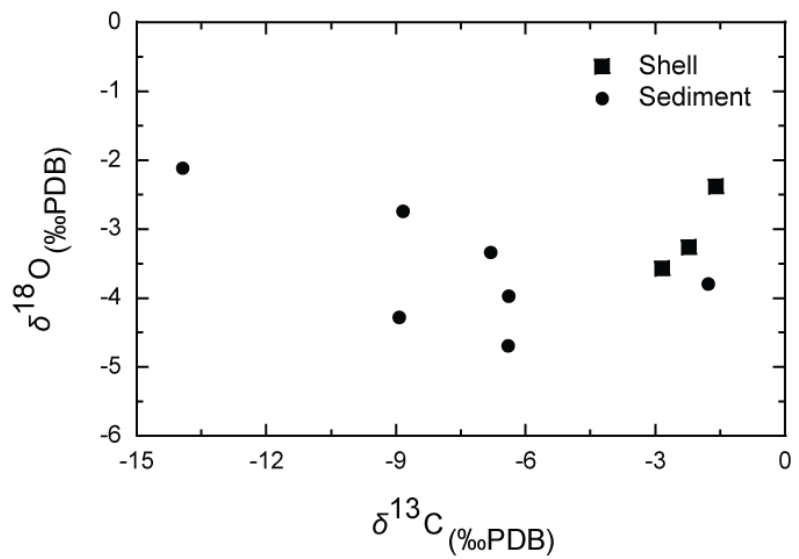

Fig. $2 \delta^{13} \mathrm{C}_{(\% \text { PDB })}$ versus $\delta^{18} \mathrm{O}_{(\% \text { PDB) }}$ plot for bivalve shells and calcareous sediments from Mio-Pliocene Nhila Anticline, southeast Bengal Basin, Bangladesh.

\section{Conclusions}

Stable carbon $\left(\delta^{13} \mathrm{C}\right)$ and oxygen $\left(\delta^{18} \mathrm{O}\right)$ isotope compositions of bivalve shell and calcareous sediment from Mio-Pliocene Nhila Anticline, southeast Bengal Basin were used to evaluate paleoclimate and paleoenvironment conditions. The $\delta^{13} \mathrm{C}_{\mathrm{PDB}}$ values ($2.81 \%$ o to $-1.56 \%$ o) in the bivalve shells show little negative excursion, and the more negative and wide variation of $\delta^{13} C_{\mathrm{PDB}}$ values of calcareous sediment samples (up to $-13.90 \%$ ) are also most probably influenced by plant root respiration of variable plant community photosynthesis paths during pedogenic processes in sediment. The $\delta^{18} \mathrm{O}_{\mathrm{PDB}}$ values in the bivalve shell and calcareous sedimentary rock samples range from $-2.39 \%$ o to $-3.57 \%$ and $-4.71 \%$ to $-2.13 \%$, respectively. The variable $\delta^{18} \mathrm{O}_{\mathrm{PDB}}$ values of the Nhila Anticline indicate diagenetic modification of carbonates, and negative $\delta^{18} \mathrm{O}_{\mathrm{PDB}}$ values suggest humid climate during the Mio-Pliocene time. Thus, the $\delta^{18} \mathrm{O}_{\mathrm{PDB}}$ values in the region are largely controlled by paleotemperature as well as strong rainfall.

Acknowledgements: We thanks to the authority of Stable Isotope Laboratory (LABISE) of the Federal University of Pernambuco, Brazil for stable carbon and oxygen isotope analyses. Thanks are also to Prof. Nishit Kumar Paul, Executive Editor and two anonymous reviewers for their helpful comments and suggestions that have substantially improved the paper.

\section{References}

Alam M, Alam MM, Curray JR, Chowdhury MLR and Gani MR. 2003. An overview of the sedimentary geology of the Bengal Basin in relation to the regional tectonic framework and basin-fill history. Sedimentary Geology 155: 179-208.

Alam MK, Hasan AKM, Khan MR and Whitney JW. 1990. Geological map of Bangladesh. Published by Ministry of Energy and Mineral Resources, Geological Survey of Bangladesh with cooperation of United States Geological Survey.

Alam MS, Keppens E and Paepe R. 1997. The use of oxygen and carbon isotope composition of pedogenic carbonates from Pleistocene palaeosols in NW Bangladesh, as palaeoclimatic indicators. Quaternary Science Reviews 16: $161-168$.

Allan JR and Matthews RK. 1977. Carbon and oxygen isotopes as diagenetic and stratigraphic tools: data from surface and subsurface of Barbados, West Indies. Geology 5: 16-20.

Allan JR and Matthews RK. 1982. Isotope signatures associated with early meteoric diagenesis. Sedimentology 29: 797-817.

Armstrong-Altrin JS, Lee YI, Verma SP and Worden RH. 2009. Carbon, oxygen, and strontium isotope geochemistry of carbonate rocks of the Upper Miocene Kudankulam Formation, Southern India: Implications for paleoenvironment and diagenesis. Chemie der ErdeGeochemistry 69: 45-60.

Armstrong-Altrin JS, Madhavaraju J, Sial AN, KasperZubillaga JJ, Nagarajan R, Flores-Castro $\mathrm{K}$ and Rodriguez JL. 2011. Petrography and stable isotope geochemistry of the Cretaceous El Abra limestones (Actopan), Mexico: Implication on diagenesis. Journal Geological Society of India 77: 349-359.

Armstrong-Altrin JS, Ramasamy S and Makhnach A. 2001. Stable isotope geochemistry and evidence for meteoric diagenesis in Kudankulam Formation, Tamil Nadu. Journal Geological Society of India 57: 39-48. 
Bellanca A, Calvo JP, Neri R and Mirto E. 1995. Lake margin carbonate deposits of Las Minas Basin, Upper Miocene, Southeastern Spain. A sedimentological and geochemical approach to the study of lacustrine and palustrine paleoenvironments. Mineralogica et Petrographica Acta 38: $113-128$.

Buonocunto FP, Sprovieri M, Bellanca A, D’Argenio B, Ferreri V, Neri R and Ferruzza G. 2002. Cyclostratigraphy and high-frequency carbon isotope fluctuations in Upper Cretaceous shallow-water carbonates, southern Italy. Sedimentology 49: 1321-1337.

Cerling TE. 1984. The stable isotopic composition of modern soil carbonate and its relationships to climate. Earth and Planetary Science Letter 71: 229-240.

Cerling TE. 1991. Carbon dioxide in the atmosphere: evidence from Cenozoic and Mesozoic paleosols. American Journal of Science 291: 377-400.

Cerling TE, Quade J, Wang Y and Bowman JR. 1989. Carbon isotopes in soils and paleosols as ecology and palaeocology indicators. Nature 341: 138-139.

Craig H. 1957. Isotopic standards for carbon and oxygen and correction factors for mass spectrometric analyses of carbon dioxide. Geochimica et Cosmochimica Acta 12: 133-149.

Dettman DL, Kohn MJ, Quade J, Ryerson FJ, Ojha TP and Hamidullah S. 2001. Seasonal stable isotope evidence for a strong Asian monsoon throughout the past 10.7 m.y. Geology 29: 31-34.

Evans P. 1932. Tertiary succession in Assam. Transactions of the Geological Institute of India 27: 155-260.

Friedman I and O'Neil JR. 1977. Compilation of stable isotope fractionation factors of geochemical interest. Washington, DC. USGS, Professional Paper, 440 K, 96 pp.

Gani MR and Alam MM. 2003. Trench-slope controlled deepsea clastics in the exposed lower Surma Group in southeastern Fold Belt of the Bengal Basin, Bangladesh. Sedimentary Geology 155: 227-270.

Hossain HMZ, Ahamed S, Armstrong-Altrin JS, Sial AN and Nowsher MN. 2012. Stable isotopes of carbon and oxygen in the Miocene sediments of the Nhila Hill Range, Cox's Bazar, Bangladesh. An International Conference on Green Chemistry for Sustainable Development 2012, Jessore Science and Technology University, Bangladesh, July 14, 2012 (Abstract).

Hossain HMZ, Roser BP and Kimura J-I. 2010. Petrography and whole-rock geochemistry of the Tertiary Sylhet succession, northeastern Bengal Basin, Bangladesh: provenance and source area weathering. Sedimentary Geology 228: 171-183.

Hudson JD. 1977. Stable isotopes and limestone lithification. Journal of the Geological Society, London 133: 637-660.

Keith ML and Weber JN. 1964. Carbon and oxygen isotopic composition of selected limestones and fossils. Geochimica et Cosmochimica Acta 28: 1787-1816.
Khan FH. 1991. Geology of Bangladesh. The University Press Limited, Dhaka, Bangladesh, 207 pp.

Marshall JD. 1992. Climatic and oceanographic isotopic signals from the carbonate rock record and their preservation. Geological Magazine 129: 143-160.

Meyers WJ and Lohmann KC. 1985. Isotope geochemistry of regionally extensive calcite cement zones and marine components in Mississippian limestones, New Mexico. In: Schneidermann, N., Harris, P.M. (Eds.), Carbonate cements. Society of Economic Paleontologists and Mineralogists Special Publication 36: 223-240.

Milliman JD and Muller J. 1977. Characteristics and genesis of shallower water and deep sea limestones. In: N.R. Anderson and A. Maahoff (Eds.), The fate of fossil fuel $\mathrm{CO}_{2}$ in the Oceans, New York, Plenum, pp. 655-672.

Nagarajan R, Sial AN, Armstrong-Altrin JS, Madhavaraju J and Nagendra R. 2008. Carbon and oxygen isotope geochemistry of Neoproterozoic limestones of the Shahabad Formation, Bhima basin, Karnataka, southern India. Revista Mexicana de Ciencias Geológicas 25: 225-235.

Nelson CS. 1988. An introductory perspective on non-tropical shelf carbonates. Sedimentary Geology 60: 3-17.

Quade J, Garzione C and Eiler J. 2007. Paleoelevation reconstruction using pedogenic carbonates. Reviews in Mineralogy \& Geochemistry 66: 53-87.

Reimann K-U. 1993. Geology of Bangladesh. Gebrüder Borntraeger, Berlin, 160 pp.

Robinson SA, Andrews JE, Hesselbo SP, Radley JD, Dennis PF, Harding IC and Allen P. 2002. Atmospheric $p \mathrm{CO}_{2}$ and depositional environment from stable-isotope geochemistry of calcrete nodules (Barremian, Lower Cretaceous, Wealden Beds, England). Journal of the Geological Society, London 159: 215-224.

Roy DK and Roser BP. 2011. Major and trace element compositions of Tertiary sedimentary successions in the NW and SE Bengal basin, Bangladesh. Geoscience Reports of Shimane University 30: 31-45.

Shackleton NJ. 1968. Depth of pelagic foraminifera and isotopic changes in Pleistocene oceans. Nature 218: 79-80.

Uddin A and Lundberg N. 1999. A paleo-Brahmaputra? Subsurface lithofacies analysis of Miocene deltaic sediments in the Himalayan-Bengal system, Bangladesh. Sedimentary Geology 123: 239-254.

Veizer J and Demovic R. 1973. Environment and climatic controlled fractionation of elements in the Mesozoic carbonate sequences of the western Carpathians. Journal of Sedimentary Petrology 43: 258-271.

Veizer J. 1983. Chemical diagenesis of carbonates; theory and application of trace element technique, in Arthur, M.A., Anderson, T.F., Kaplan, I.R., Veizer, J., Land, L.S. (eds.), Stable Isotopes in Sedimentary Geology. Society of Economic Palaeontologists and Mineralogists, pp. 3-100.

Wright EK. 1987. Stratification and paleocirculation of the Late Cretaceous Western Interior Seaway of North America. Geological Society of America Bulletin 99: 480-490.

Manuscript received on 1 December 2013 and revised on 21 December 2013 